\title{
Taxonomic identity of invasive rabbits in Cuba: first record of Eastern Cottontail, Sylvilagus floridanus (Mammalia: Lagomorpha)
}

\author{
Carlos A. Mancina ${ }^{1 *}$, Efrén García Tió ${ }^{2}$, Rafael Borroto-Páez ${ }^{3}$, Héctor M. Díaz ${ }^{1}$ and Fernando A. Cervantes ${ }^{4}$ \\ 1 Instituto de Ecología y Sistemática, Carretera de Varona km. 3 1⁄2 Capdevila, Boyeros, C.P. 10800, La Habana, Cuba \\ 2 Federación Cubana de Caza Deportiva. Calle $7^{\mathrm{ma}}$ \# 21808. Playa, C.P. 12200, La Habana, Cuba \\ 3 Sociedad Cubana de Zoología \\ 4 Instituto de Biología, Universidad Nacional Autónoma de México. A.P 70-153, C.P. 04510, DF, México \\ * Corresponding author. E-mail: mancina@ecologia.cu
}

\begin{abstract}
In islands of the West Indian zoogeographical region, rabbits are not native, and wild populations are the result of introductions. Oryctolagus cuniculus is the only lagomorph listed among the introduced mammals of the Cuban archipelago. We analyzed specimens of wild rabbits and we report the occurrence of Sylvilagus floridanus for the first time in Cuba. Capture data suggest that their distribution is currently limited to the westcentral region of the island. However, the niche models showed high climatic suitability throughout the majority of Cuba, suggesting a high expansion probability.
\end{abstract}

Key words: Eastern Cottontail, introduced mammal, new record, niche modeling, Oryctolagus cuniculus, West Indies

In Cuba, as in other islands of the West Indian zoogeographical region (sensu Hershkovitz 1958), rabbits are not native, and wild populations are the result of introduction for hunting and cuniculture (Long 2003). The origin of wild rabbit populations in Cuba is uncertain, but their introduction likely dates to the first years of Spanish colonization. Rodríguez-Ferrer (1876) wrote that domesticated forms of Oryctolagus cuniculus Linnaeus, 1758 were imported to Cuba from France, Spain and the U.S.A., probably in the early nineteenth century or just before. However, he suggested that these introduced rabbits failed to establish enduring wild populations in Cuba due to low availability of food and the wet climate. Moreover, Varona (1974) mentioned that wild European rabbits could have been imported from the Canary Islands to Cuba about 188 os. However, based on the currently available information it is not possible to verify the exact origin or introduction date.
The European rabbit, O. cuniculus, has been introduced to more than 800 islands worldwide resulting populations in the wild (Long 2003). Perhaps because of the widespread proliferation of $O$. cuniculus throughout the world, Cuban wild rabbit populations are assumed to comprise only this species. In fact, $O$. cuniculusis the only lagomorph listed among the introduced mammals of the Cuban archipelago and in official documents that detail legal regulations and hunting guides (Varona 1974; González et al. 1994; Chamizo 2004; Anonymous 2008; Borroto-Páez 2009). However, we are unaware of any biological study on wild rabbits in Cuba that might verify this presumed species identification. As a result, we analyzed specimens of wild rabbits hunted from several localities in Cuba. Surprisingly, all specimens were identified as Sylvilagus floridanus Allen, 1890.

In this paper, we therefore report the occurrence of $S$. floridanus and scientifically document, for the first time, this genus and species in Cuba. Additionally, we modeled the environmental niche of $S$. floridanus in its native range and projected the model to the Cuban archipelago in order to estimate the potential distribution in this species throughout the Cuban archipelago. Climate is an important predictor of the establishment success of invasive species (Bomford et al. 2009), and ecological niche modeling has been demonstrated to be effective for assessing the potential distributions of introduced or invasive species (Jeschke and Strayer 2008; Taylor et al. 2012). The climatic suitability maps would provide assistance for management and prioritizing areas for surveillance of this invasive species in Cuba.

We examined 17 adult wild rabbit skulls collected, between May 2012 and June 2014, from localities in western (Pinar del Río and Artemisa provinces) and central (Matanzas and Villa Clara provinces) Cuba. 
These Cuban wild rabbit skulls were compared with skulls of the European rabbit (O. cuniculus) and other rabbit species deposited in the Field Museum of Natural History (Chicago, IL, USA) and the Mammal Collection from the Instituto de Biología (Universidad Nacional Autónoma de México); in addition, we used species keys (Hall 1981; Cervantes and Lorenzo 1997) for identification at the species level. Cranial measurements were taken following Diersing and Wilson (1980) using a digital caliper (error $\pm 0.01 \mathrm{~mm}$ ). All measured skulls are deposited in the Collection of Mammals at the Instituto de Ecología y Sistemática, in Havana, Cuba.

Voucher specimens: Colección de Mamíferos del Instituto de Ecología y Sistemática, La Habana, Cuba (acronym: CZACC), CZACC 1.5551-1.5557 (7 specimens); material non-catalogued (10 specimens). Comparative material: O. cuniculus (Field Museum of Natural History: FMNH), FMNH 6455-6457; FMNH 90610-90609; FMNH 57229. S. floridanus, FMNH 73339; FMNH 7740-7742; FMNH 57168; FMNH 15949-15950; FMNH 198936-198941.

Because the ecology of wild rabbits in Cuba has not been previously studied, we also examined 42 adult rabbits in order to collect data pertaining to sex ratio, reproductive status, and body mass. These rabbits were collected between June 2013 and July 2014 from a rabbit population in northeastern Artemisa province. The study area, at $90 \mathrm{~m}$ above sea level (a.s.l.), is covered in small patches of secondary vegetation and agricultural fields (e.g., sugar cane).

The ecological niche was modeled with the MaxEnt software (Phillips et al. 2006). We used 2294 georeferenced presence points that constitute the distribution of $S$. floridanus in mainland America and 26 records from invaded range in $\mathrm{Cuba}$. All georeferenced data of native range were obtained from the Global Biodiversity Information Facility (GBIF) database (http://data.gbif.org). To reduce the clusters of localities that might create bias in environmental space, we used localities that were at least $5 \mathrm{~km}$ apart. As predictors, we used the following at a spatial resolution of 30 minutes, altitude and uncorrelated bioclimatic layers (pairwise Pearson correlation with $\mathrm{r}<0.70$ ): maximum temperature of the warmest month, annual temperature range, mean temperature of wettest quarter, mean temperature of coldest quarter, annual precipitation, precipitation seasonality, precipitation of warmest quarter, and precipitation of coldest quarter (Hijmans et al. 2005).

We ran the Maxent models using the default setting (iterations 500, convergence threshold 0.00001, and regularization value1). The native plus invasive presence points were randomly partitioned into 1,740 (75\%) training and 580 (25\%) testing datasets with 10 subsample replicates to evaluate model performance. Model performance was evaluated by measuring the area under the Receiver Operating Characteristic (ROC) curve (AUC).
AUC is a measure that ranges from 0.5 (random accuracy) to a maximum value of 1.0 (perfect discrimination) (Peterson et al. 2011). The "10 percentile training presence" threshold value was used to discriminate suitable from non-suitable habitat. This threshold may to reduce the overly extensive prediction when many calibration localities exist (Radosavljevic and Anderson, 2014). The ecological niche model generated for $S$. floridanus was then projected onto both the native range and the Cuban archipelago to assess the potential distribution, and the presence points in Cuba were plotted on the potential distribution map.

All analyzed specimens of the wild Cuban rabbit were distinguishable from $O$. cuniculus by their relatively smaller size and shorter ears. Whereas $O$. cuniculus typically exhibit a total body length greater than 490 $\mathrm{mm}$ and ear length greater than $80 \mathrm{~mm}$, our specimens exhibited total body lengths (mean \pm standard deviation) of $377.5 \pm 35.3 \mathrm{~mm}$ and ear lengths (from notch) of $61.3 \pm 2.4 \mathrm{~mm}$. In addition to these differences in external characteristics, we also discovered distinct differences in skull morphology between wild Cuban rabbit specimens and $O$. cuniculus specimens. One major skull characteristic that allowed us to distinguish our specimens from Oryctolagus genus is the tip of the posterior extension of supraorbital process: whereas in our specimens this touched the braincase, this tip is free of the braincase in Oryctolagus (Figure 1).

The comparative analysis of external and skull characteristics allowed us to further identify our specimens to the species level as $S$. floridanus, as the specimens were distinguishable from other potential congeners according to the diagnostic criteria described by Hall (1981) and Cervantes and Lorenzo (1997). In particular, the pelage of $S$. floridanus was usually reddish-brown on the upper parts and white on the venter and tail, and the nuchal patch was present but not very pronounced in most individuals (Figure 2). Furthermore, the mean body mass was $1078.1 \pm 86.2 \mathrm{~g}$ for adult males and $1221.5 \pm 297.5 \mathrm{~g}$ for adult females, which is comparable with North American populations of S. floridanus (e.g., Chapman et al. 1980; Bond et al. 2004). Because of the wide continental distribution of $S$. floridanus, their external and cranial characteristics vary highly among localities. However, the cranial measurements from Cuban specimens (Table 1) are within the observed range of most subspecies of $S$. floridanusin both west-central Mexico (Diersing and Wilson 1980) and east-central U.S.A (Chapman et al. 1980).

Ecological data from the samples obtained from Artemisa province suggest a 1:1 sex ratio (21 males and 21 females), which conforms to the sex ratio documented for this species in North American populations (Bond et al. 2004). We observed pregnancy between March 


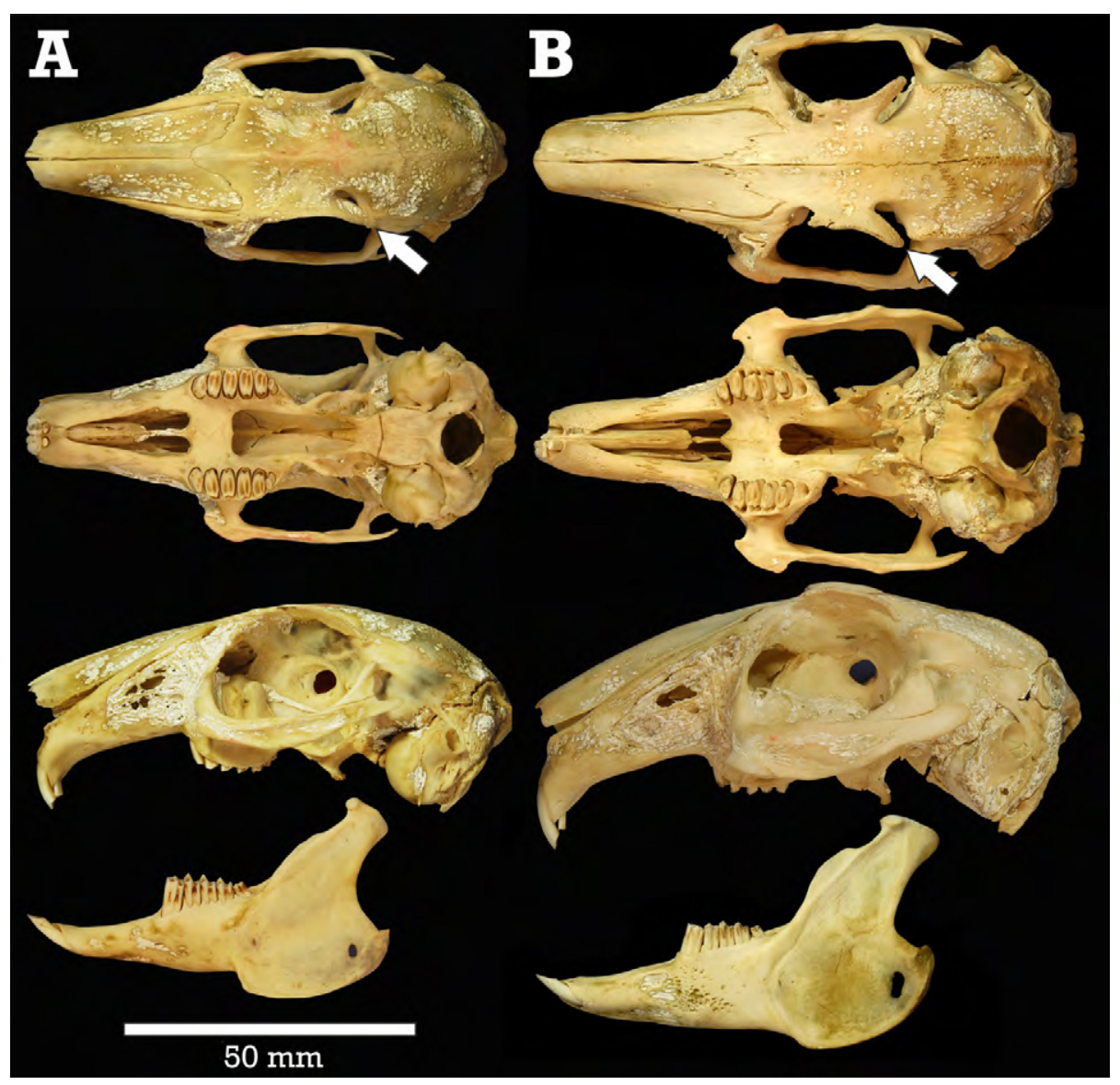

Figure 1. Views of the skull and mandible of Sylvilagus floridanus (A; adult female, CZACC-5553) from Cuba compared with Oryctolagus cuniculus (B). The arrows indicate the tip of the posterior extension of the supraorbital process, which touches the braincase in Sylvilagus but remains free of the braincase in Oryctolagus.

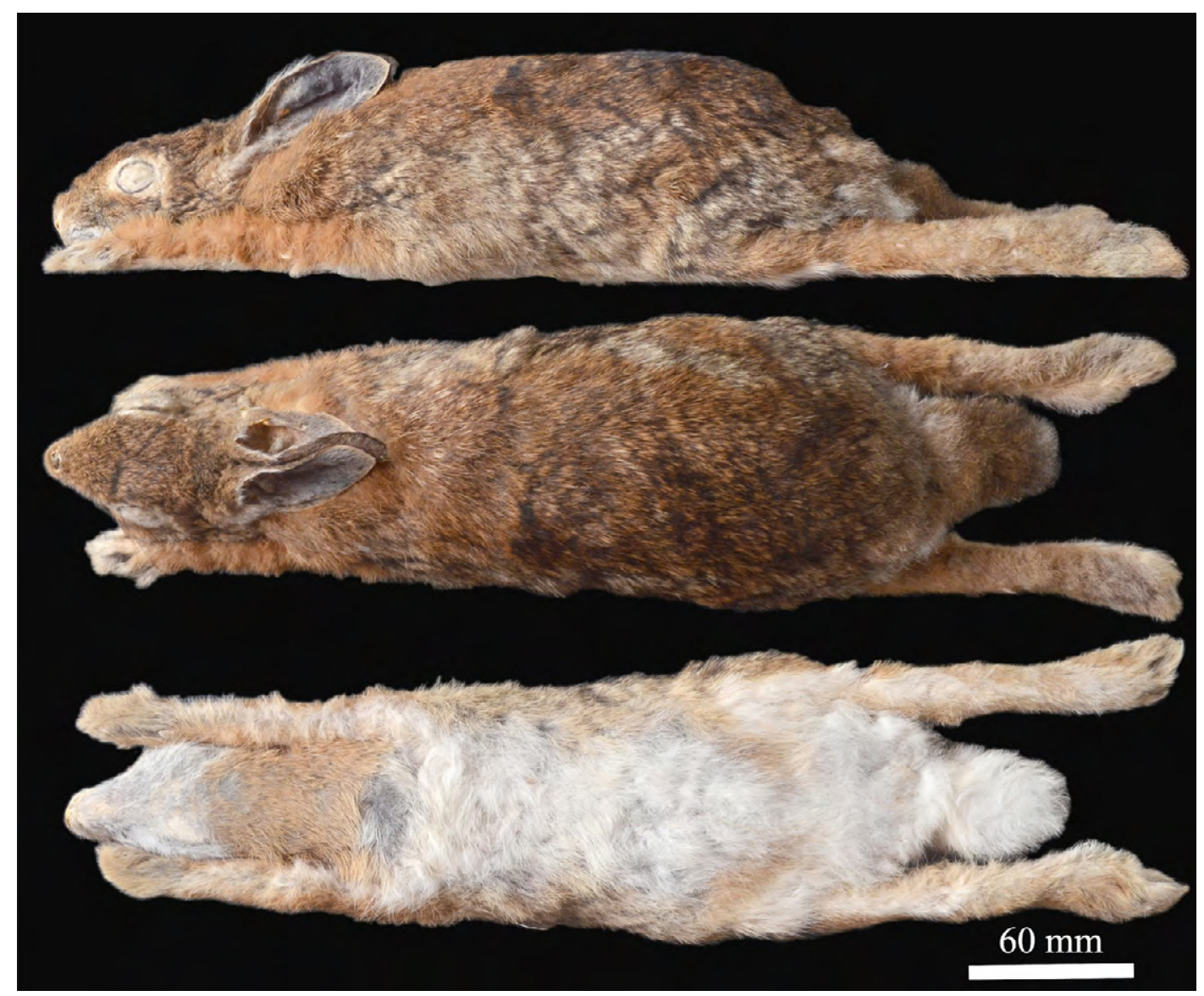

Figure 2. Dorsal, ventral, and lateral views of the skin of Sylvilagus floridanus, adult male CZACC 1.5557. Collected in Artemisa province, Cuba. 
Table 1. Cranial measurements (mean \pm standard deviation, in $\mathrm{mm}$ ) of specimens of Sylvilagus floridanus from Cuba. For measurement definitions see Diersing and Wilson (1980).

\begin{tabular}{lll}
\hline Variables & Males $(\boldsymbol{n}=\mathbf{8})$ & Females $(\boldsymbol{n}=\mathbf{9})$ \\
\hline Greatest skull length & $73.9 \pm 1.73$ & $73.28 \pm 2.18$ \\
Basilar length & $58.9 \pm 0.72$ & $58.8 \pm 2.21$ \\
Zygomatic breadth & $34.3 \pm 0.28$ & $34.53 \pm 0.61$ \\
Braincase breadth & $24.5 \pm 0.87$ & $24.14 \pm 0.74$ \\
Interorbital breadth & $18.67 \pm 0.51$ & $18.06 \pm 0.69$ \\
Palatal length & $29.33 \pm 1.11$ & $30.44 \pm 1.46$ \\
Bullar length & $11.7 \pm 0.95$ & $11.34 \pm 0.83$ \\
Mastoid width & $24.7 \pm 0.17$ & $23.98 \pm 1.29$ \\
Height of braincase & $28.67 \pm 1.4$ & $29.68 \pm 1.54$ \\
Maxillary toothrow & $11.73 \pm 0.97$ & $11.98 \pm 0.7$ \\
Diameter of external auditory meatus & $3.97 \pm 0.12$ & $3.98 \pm 0.54$ \\
Mandible total length & $52.1 \pm 0.9$ & $51.66 \pm 1.43$ \\
Mandibular toothrow & $12.33 \pm 1.53$ & $12.1 \pm 0.23$ \\
\hline
\end{tabular}

and July with two and three embryos in each female. This litter size is less than previously reported in some continental populations (e.g., Ecke 1955). However, both breeding season and litter size likely vary among populations (Bond et al. 2004), as Barkalow (1962) suggested that cottontails in northern latitudes produce larger litters than in southern latitudes.

Anecdotal data of harvested cottontails in Cuba suggest that their distribution is limited to the west-central region of the island. However, wild rabbits are apparently more abundant on the Habana-Matanzas Plain and have not been captured nor sighted further east than Sancti Spíritus province in central Cuba. Based on our occurrence data, these rabbits are most typically found at sites of low altitude ( $<250 \mathrm{~m}$ a.s.l.), where annual temperature ranges from $23.5-25.5^{\circ} \mathrm{C}$ and annual precipitation between ranges from $1200-1600 \mathrm{~mm}$. Generally, the rabbits are associated with crop fields, grasslands, and scrublands. Although anecdotal, these observations conform to expectations presented by Betolino et al. (2011a), in which distribution models based on landscape attributes found that the presence of introduced S. floridanus in northwestern Italy is favored by crops and meadows with high ecotones extension and wide hydrographic networks associated with riverside vegetation.

Our own predictive models had high AUC values ( 0.805 \pm 0.009 for training and $0.789 \pm 0.012$ for test), indicating reasonable model performance. The models showed high climatic suitability for $S$. floridanus throughout the majority of Cuba, with $88,707 \mathrm{~km}^{2}$ (ca. $87 \%$ of the island) considered suitable for Eastern Cottontails (Figure 3). The models predicted that only relatively small areas in Camagüey province, as well as the highlands in the most eastern region of Cuba, do not present suitable environments for this species.

In an informal interview of Cuban hunters in the preparation of this paper, we determined that four decades ago rabbit sighting were limited around the Habana-Matanzas Plain. However, in the last twenty years rabbits have been hunted in localities in the Central region in Villa Clara and Sancti Spíritus provinces. Because of absence of geographic barriers as well as low diversity of native competitors or predators, the models suggest a high expansion probability of this invasive species. As occurred in northwestern Italy (Bertolino et al. 2011b), this rabbit could continue to expand its distribution range on Cuba.

The specimens analyzed in this study were obtained from localities that cover the most part of area of occupancy known of Cuban wild rabbits. Because all specimens were positively identified as $S$. floridanus, the current existence of feral populations of the European rabbit (O. cuniculus) in Cuba is currently unknown. However, European rabbits are very commonly found in captivity throughout Cuba, and it is therefore possible, and perhaps even certainly, that $O$. cuniculus has been either accidentally or deliberately released by farmers. In fact, some hunters report that in certain localities two distinguishable types of rabbits occur in the wild. In addition, a specimen identified as O. cuniculus (MCZ41256), collected in southeast of Havana province, is deposited in the Museum of Comparative Zoology, Harvard University; although details of the habitat where it was collected are unknown.

The arrival of the Eastern Cottontail rabbit to Cuba likely occurred through intentional introductions from the U.S.A. for hunting purposes. This species is the most important game animal in the U.S.A. (Chapman et al. 1982) and was the subject of massive introductions and translocations within the U.S.A.during the first half of the twentieth century (Chapman and Morgan 1973; Hall 1981). In the early twentieth century, the intentional introduction of non-native species was a common practice in Cuba, and a government program to enrich Cuban fauna was responsible for introducing numerous species from the U.S.A. (Gómez de la Maza 1932). Although we have not yet found reports specifically documenting the introduction of $S$. floridanus in Cuban hunting bulletins, gray literature, or other publications, likely this species could have been imported and released around Havana, and we are currently in the process of researching this historical issue. To date, exists only a single report of Sylvilagus genus elsewhere in the West Indies (Dominican Republic; Ministerio de Medio Ambiente y Recursos Naturales 2012), but their specific status is unknown.

As for other islands of the West Indies, Cuba has a depauperate native mammal fauna (Borroto-Páez and Mancina 2011). This zoogeographic subregion has been the subject of many mammal introductions (Massetti 2011; Borroto-Páez and Woods 2012). The ecological impacts of many invasive species on these islands have 


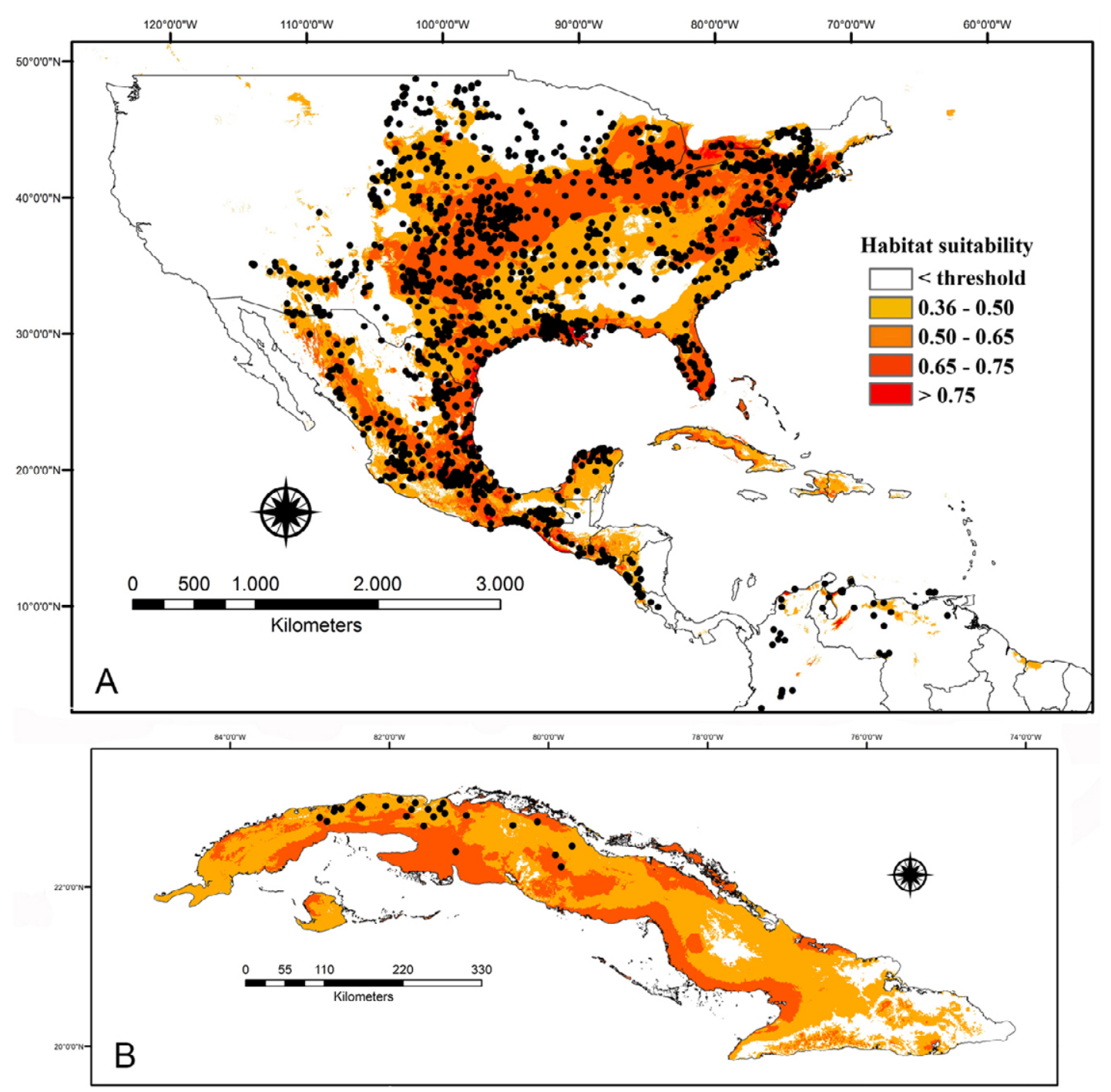

Figure 3. Ecological niche model for Sylvilagus floridanus based on presence records from native range in United States to northern South America and records from the invaded range in Cuba (A). The environmentally suitable area (orange gradient) was based on "10th percentile training presence" threshold; points represent occurrence records from GBIF. Projection of the model of predicted suitability to the Cuban archipelago (B); points represent localities where the species have been captured or sighted.

not been deeply evaluated, and the effects attributed to most species are based on limited or circumstantial data. In Cuba, there is no available evidence of rabbit-induced damage on native plants, although it is known that rabbits consume some commercial crops and sugar cane seedlings. However, as in other countries, rabbits can affect plant communities by over-grazing or by dispersing seeds of invasive plants (Bell et al. 1999; Fernandez and Saiz 2007). Moreover, S. floridanus hosts parasites and is a possible vector of diseases that can be transmitted to native fauna and humans (e.g., Jacobson et al. 1978; Cooney et al. 2005). This species can be a carrier of myxomatosis, which is lethal to rabbits (O. cuniculus) used for food production, as well as the West Nile Virus, an agent of significant human and veterinary disease (Tiawsirisup et al. 2005). For example, the introduction of $S$. floridanus to Italy also resulted in the introduction of several species of protozoan intestinal parasites of North American origin (Bertolino et al. 2010).
Due to the extensive home range, high reproductive rates as well as capacity to use a wide diversity of habitats (Chapman et al. 1980; Chapman and Ceballos 1990), rabbit populations should be controlled and monitored by Cuban conservation and health authorities. Of special concern is the possibility of the species' expansion or introduction to protected areas and offshore cays in the Cuban archipelago. There the ecological impacts might severe, affecting the integrity of autochthonous vegetation and forest regeneration, beside could compete with some species of endemic and endangered rodents (hutias). This study therefore makes an important contribution to updating the invasive species threat to the Cuban archipelago and the possible expansion of $S$. floridanus. We emphasize the need for additional study of this species in order to identify its geographic scope, life-history, and potential ecological and health impacts, for the purpose of science-based management and risk-reduction. 


\section{ACKNOWLEDGEMENTS}

We are grateful to Ernesto Morell, Maday Pedroso, José $M$. Fuentes and other hunters and farm-owners for providing rabbit samples and information. Special thanks to Rubén Chamizo for encouraging us to pursue this study through their comments about the possible presence of Sylvilagus in Cuba. Thanks to Boris A. Fabres and Jeremy C. Crawford for their thoughtful comments on the manuscript.

\section{LITERATURE CITED}

Anonymous. 2008. Resolución No. 626/2008 del 19 de Septiembre del 2008. Calendario de Caza 2008-2009. Gaceta Oficial de la República de Cuba 1074-1085.

Barkalow, F.S. Jr. 1962. Latitude related to reproduction in the cottontail rabbit. Journal of Wildlife Management 26(1):32-37. doi: $10.2307 / 3798165$

Bell, A. C., P. Byrne and S. Watson. 1999. The effect of rabbit (Oryctolagus cuniculus) grazing damage on the growth, botanical composition and yield of a ryegrass re-seed. Annals of Applied Biology 135(1): 417-424.

Bertolino, S., L. Hofmannová, M. Girardello and D. Modry. 2010. Richness, origin and structure of an Eimeria community in a population of Eastern cottontail (Sylvilagus floridanus) introduced into Italy. Parasitology 137: 1179-1186. doi: 10.1017/ Soo31182009992095

Bertolino, S., B. Ingegno and M. Girardello. 2011a. Modelling the habitat requirements of invasive Eastern cottontail (Sylvilagus floridanus) introduced to Italy. European Journal of Wildlife Research 57:267-274. doi: 10.1007/s10344-010-0422-9

Bertolino, S., A. Perrone, L. Gola and R. Viterbi. 2011b. Population density and habitat use of the introduced Eastern Cottontail (Sylvilagus floridanus) Compared to the Native European Hare (Lepus europaeus). Zoological Studies 50(3): 315-326.

Bomford, M., F. Kraus, S.C. Barry and E. Lawrence. 2009. Predicting establishment success for alien reptiles and amphibians: a role for climate matching. Biological Invasions 11(3): 1387-3547. doi: 10.1007/s10530-008-9285-3

Bond, B.T., J.L. Bowman, B.D. Leopold, L.W. Burger, K.D. Godwin and C.M. Class. 2004. Demographics, morphometrics, and reproductive characteristics of Eastern Cottontails (Sylvilagus floridanus) in Mississippi. Journal of the Mississippi Academy of Sciences 49(4): 220-224.

Borroto-Páez, R. 2009. Invasive mammals in Cuba: an overview. Biological Invasions 11: 2279-229o. doi: 10.1007/s10530-0089414-z

Borroto-Páez, R. and C.A. Woods. 2012. Status and impact of introduced mammals in the West Indies; pp. 241-258, in: R. Borroto-Páez, C.A. Woods and F.E. Sergile (eds.). Terrestrial mammals of the West Indies. Contributions. Florida: Wocahoota Press and Florida Museum of Natural History.

Borroto-Páez, R. and C.A. Mancina. 2011. Mamíferos en Cuba. Vasa: UPC Print. 271 pp.

Cervantes, F.A. and C. Lorenzo.1997. Sylvilagus insonus. Mammalian Species 568: 1-4.

Chamizo, R. 2004. Caza y sostenibilidad: una polémica de actualidad también en Cuba. Revista Forestal Baracoa 24 (Número Especial): 85-92.

Chapman, J.A. and G. Ceballos. 199o. The cottontails; pp. 95-110, in: J.A. Chapman and J.E.C. Flux (eds.). Rabbits, hares and pikas. Status survey and conservation action plan. Gland: IUCN.

Chapman, J.A. and R.P. Morgan. 1973. Systematic status of the cottontail complex in western Maryland and nearby West Virginia. Wildlife Monography 36: 1-54.
Chapman, J.A., J.G. Hockman and M.M. Ojeda. 1980. Sylvilagus floridanus. Mammalian Species 136: 1-8.

Chapman, J.A., J.G. Hockman and W.R. Edwards. 1982. Cottontails; pp. 83-123, in: J.A. Chapman and G.A. Feldhamer (eds.). Wild mammals of North America. London: The Johns Hopkins University Press.

Cooney, J.C., W. Burgdorfer, M.K. Painter, and C.L. Russell. 2005. Tick infestations of the eastern cottontail rabbit (Sylvilagus floridanus) and small rodentia in northwest Alabama and implications for disease transmission. Journal of Vector Ecology 30(2): 171-180.

Diersing, V.E., and D.E. Wilson. 1980. Distribution and systematics of the rabbits (Sylvilagus) of West-Central Mexico. Smithsonian Contributions to Zoology 297: 1-34. doi: 10.5479/si.00810282.297

Ecke, D.H. 1955. The reproductive cycle of the Mearns cottontail in Illinois. American Midland Naturalist 53:294-311. doi: $10.2307 / 2422069$

Fernandez, A. and F. Saiz. 2007. The European Rabbit (Oryctolagus cuniculus L.) as seed disperser of the invasive Opium Poppy (Papaver somniferum L.) in Robinson Crusoe Island, Chile. Mastozoología Neotropical 14(1):19-27. http://ref.scielo.org/ fs $784 \mathrm{x}$

Gómez de la Maza, F. 1932. Enriqueciendo nuestra fauna. Revista de Agricultura, Comercio y Trabajo 14(6): 61-63.

González, A., N. Manójina and A. Hernández. 1994. Mamíferos del Archipiélago de Camagüey, Cuba. Avicennia 1: 51-56.

Hall, E.R. 1981. The mammals of North America. Vol. 1. New York: John Wiley and Sons. 600 pp.

Hershkovitz, P. 1958. A geographical classification of Neotropical mammals. Fieldiana, Zoology 36: 581-620. doi: 10.5962/bhl. title.3004

Hijmans, R.J., S.E. Cameron, J.L. Parra, P.G. Jones and A. Jarvis. 2005. Very high resolution interpolated climate surfaces for global land areas. International Journal of Climatology 25: 1965-1978. doi: 10.1002/joc.1276

Jacobson H.A., R.L. Kirkpatrik and B.S. McGinness. 1978. Disease and physiologic characteristics of two cottontail populations in Virginia. Wildlife Monography 6o: 1-53. http://www.jstor.org/ stable/3830590

Jeschke, J.M. and D.L. Strayer. 2008. Usefulness of bioclimatic models for studying climate change and invasive species. Annals of the New York Academy of Sciences 1134: 1-24. doi: 10.1196/ annals.1439.002

Long, J.L. 2003. Introduced mammals of the world: their history, distribution and influence. Collingwood: CSIRO Publishing. 589 pp.

Massetti, M. 2011. Anthropochorous mammals of the Old World in the West Indies. Mammalia 75: 113-142. doi: 10.1515/ mamm.2011.012

Ministerio de Medio Ambiente y Recursos Naturales. 2012. Estrategia Nacional de Especies Exóticas Invasoras Realizado en el marco del proyecto "Mitigando las amenazas de las especies exóticas invasoras en el Caribe Insular". Santo Domingo: República Dominicana. 35 pp. http://www.semarena.gov.do

Peterson, A.T., J. Soberón, R. Pearson, R. Anderson, E. MartínezMeyer, M. Nakamura and M.B. Araújo. 2011. Ecological niches and geographic distributions. Princeton: Princeton University Press. 314 pp.

Phillips, S.J., R.P. Anderson and R.E. Schapire. 2006. Maximum entropy modeling of species geographic distributions. Ecological Modelling 190: 231-259. doi: 10.1016/j.ecolmodel.2005.03.026

Radosavljevic, A. and R.P. Anderson. 2014. Making better MAXENT models of species distributions: complexity, overfitting and evaluation. Journal of Biogeography 41: 629-643. doi: 10.1111/jbi.12227

Rodríguez-Ferrer, M. 1876. Naturales y civilización de la grandiosa Isla de Cuba. Estudios variados y científicos, al alcance de todos, 
y otros históricos, estadísticos, y políticos. Madrid: Imprenta de J. Nogera. $942 \mathrm{pp}$.

Taylor, S., L. Kumar, N. Reid and D.J. Kriticos. 2012. Climate change and the potential distribution of an invasive shrub, Lantana camara L. Plos One 7(4): e35565. doi: 10.1371/journal. pone.0035565

Tiawsirisup, S., K.B. Platt, B.J. Tucker, and W.A. Rowley. 2005. Eastern Cottontail Rabbits (Sylvilagus floridanus) develop West Nile virus viremias sufficient for infecting select mosquito species. Vector-Borne and Zoonotic Diseases 5(4): 342-350. doi: 10.1089/vbz.2005.5.342

Varona, L.S. 1974. Catálogo de los mamíferos vivientes y extinguidos de las Antillas. La Habana: Academia de Ciencias de Cuba. 139 pp.
Author contributions: CAM and FAC identified the species; EGT and HMD collected data and specimens from field and prepared the study skulls; RBP and FAC collected the data from museum specimens; CAM and RBP analyzed the data and wrote the text; CAM, EGT, RBP, HMD and FAC reviewed the text.

Received: 2 August 2015

Accepted: 27 October 2015

Academic editor: Paúl M. Velazco 